\title{
Pople, Schneider, and Bernstein - A truly seminal treatise of NMR ${ }^{1}$
}

\author{
John D. Roberts
}

\begin{abstract}
The appearance of the authoritative and comprehensive book, High-Resolution Nuclear Resonance Spectroscopy, by John A. Pople, William G. Schneider, and Harold J. Bernstein in 1959 came at just the right time for chemists and other scientists to develop a clear vision of the wide breadth of applications of this critical emerging field and, in addition, to have the opportunity to learn the underlying basic theory in substantial detail.
\end{abstract}

Key words: Pople, Schneider, Bernstein, NMR theory, NMR applications.

Résumé : Le traité compréhensif de John A. Pople, William G. Schneider et Harold J. Bernstein, High-Resolution Nuclear Resonance Spectroscopy a fait autorité et son apparition en 1959 est arrivée juste au bon moment pour permettre aux chimistes et aux scientifiques de se faire une idée claire de l'étendue des applications de ce nouveau domaine critique alors en émergence et, de plus, d'avoir une opportunité d'apprendre en détail la théorie de base sousjacente.

Mots clés : Pople, Schneider, Bernstein, théorie de la RMN, applications de la RMN.

[Traduit par la Rédaction]

\section{Introduction}

The progress of chemistry often occurs in spurts, especially as new ideas emerge or new understandings are achieved. Many such spurts are facilitated by especially significant books. Some of these books are of such nature to stay in print for many years; others are more ephemeral because they appear soon after a new field opens and although they may be especially timely when they first appear, before long they may be left behind as their impact leads to new applications and new insights. The first category includes such books as Lewis and Randall's Thermodynamics (1), Pauling and Wilson's Quantum Mechanics (2), Pauling's Nautre of the Chemical Bond (3), Sidgwick's Organic Chemistry of Nitrogen (4), and Hammett's Physical Organic Chemistry (5).

In 1952, while at MIT, I first was exposed to the possibilities of NMR in chemistry in a personal lecture by Richard A. Ogg of Stanford, but my level of comprehension of the physics involved was insufficient to take any action other than to note that Ogg's boundless enthusiasm surely meant that, for someone, NMR would be a winning research area. Two years later, William D. Phillips showed me actual spectra of organic compounds and what could be gleaned from them, especially such information as the rates of rotation about the $\mathrm{C}-\mathrm{N}$ bond of $N, N$-dimethylformamide. That exposure led to an intense campaign to get a NMR spectrome-

Received 30 March 2005. Published on the NRC Research Press Web site at http://canjchem.nrc.ca on 1 December 2005.

J.D. Roberts. Crellin Laboratory (164-30), California Institute of Technology, 1201 E. California Boulevard, Pasadena, CA 91125, USA (e-mail: robertsj@caltech.edu).

${ }^{1}$ This article is part of a Special Issue dedicated to organic reaction mechanisms. ter at Caltech to be under the general supervision of the organic group. Linus Pauling was unenthusiastic, because he thought such a spectrometer would be best supervised by more knowledgeable persons with experience in magnetic resonance and expertise in electronics. He relented when it was pointed out that NMR should be well-suited to investigate the borderline between resonance and tautomerism. Our installation was one of the very first Varian NMRs to be installed in an academic institution.

My initial plan was to determine the structure of diketene, a festering problem for many years, but Herbert S. Gutowsky (probably the first chemist to do extensive research on NMR with self-built instrumentation) got there first (6). A secondary goal was to determine the structure of Feist's acid, which was successful in confirming the material to be 3-methylene-1,2-cyclopropanedicarboxylic acid (7). But actually, my first paper using NMR was concerned with whether the very broad line observed for the $\mathrm{N}-\mathrm{H}$ proton of pyrrole was the result of proton exchange or (as it turned out) ${ }^{14} \mathrm{~N}$ quadrupolar interactions (8). I ran these and several hundred other NMR spectra over the next year with little clue as to the basics of how an NMR spectrometer actually worked. But as I caught on to more of it, my enthusiasm grew, and in the summer of 1958, an invitation to speak at a Reaction Mechanisms Conference at Bryn Mawr provided an opportunity to give a lecture on the subject to physical organic chemists. The response was so favorable, a missionary zeal quickly developed to write a book based on the lecture material.

It did not take long to realize that when one writes a book about an especially fast moving field, such as NMR, it is somewhat like writing in water. I experienced that feeling in 1959 with my book Nuclear Magnetic Resonance (9), even though my purpose of the book was simple: an alert to organic chemists of the possibilities of NMR in their area 
Fig. 1. (a) John A. Pople (10/31/1925 - 3/15/2004) was born in Somerset, UK, showed strong mathematical skills at a very early age, received a Ph.D. in mathematics at Cambridge in 1948, started in NMR in 1955, worked two summers at NRC in Ottawa with Schneider and Bernstein. His later interests were in quantum theory of molecular properties, he was knighted in 2003 and awarded the Nobel Prize in Chemistry in 1998. (Photo taken in the 1950s.) (b) William G. Schneider (6/1/1915 -) was born in Saskatchewan, took B.Sc. and M.S. at the University of Saskatchewan, received a Ph.D. in physical chemistry at McGill in 1941, worked as a postdoctoral fellow at Harvard (1941-1943), vice president and president (1965-1980) of the Pure Chemistry Division at NRC (1943-1980), and he was awarded the Order of Canada in 1977. (Photo taken in the 1950s from the NRC Archives.) (c) Harold J. Bernstein (8/26/1914 12/14/84) was born in Toronto and had his advanced education at the University of Toronto culminating with a Ph.D. in physical chemistry in 1938, postdoctoral scholar in Copenhagen (1938-1940), worked with NRC in chemistry from 1946 to his retirement in 1981. Following the publication of PSB, he gradually moved to research in Raman spectroscopy. (Photo taken in 1967 from the NRC Archives.)
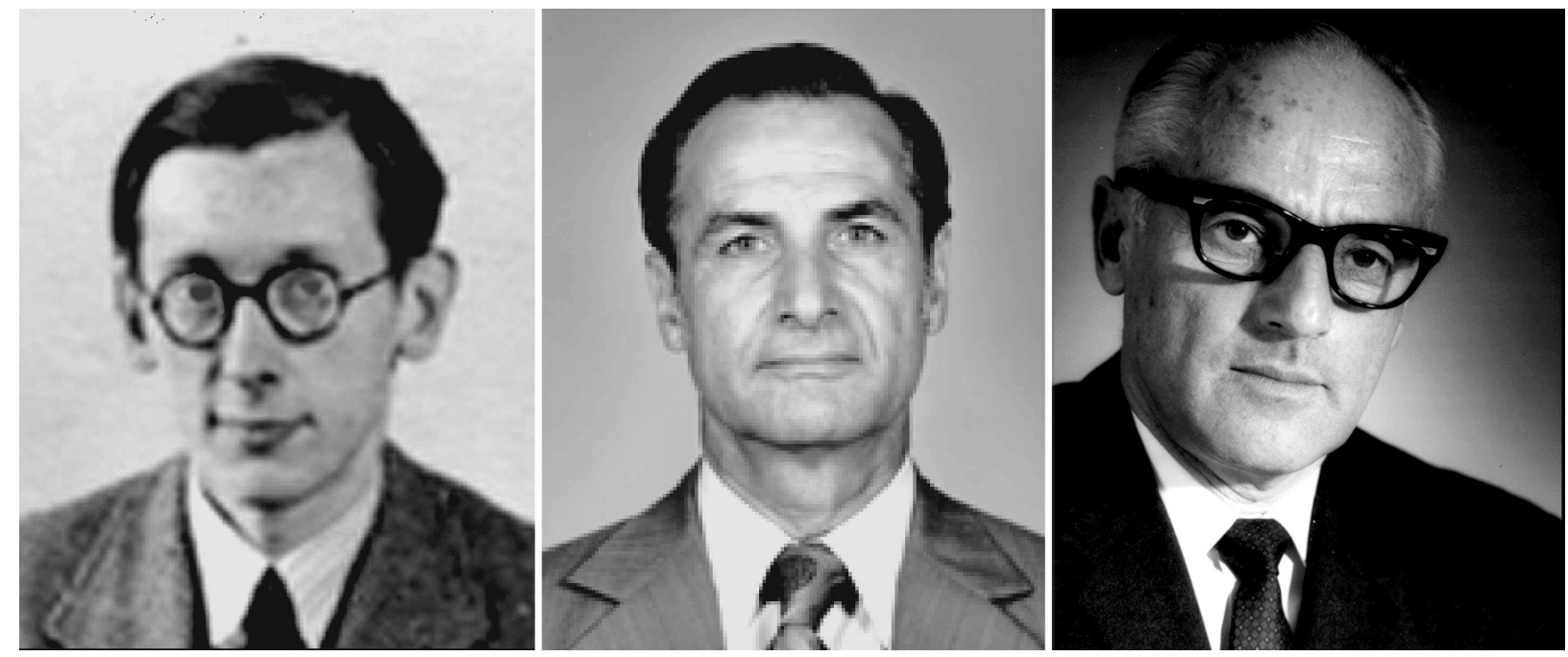

and a hope of imparting simple general ideas of how it worked - at least at the level I knew it then. This book did, however, achieve two distinctions: $(a)$ being the first advanced chemistry monograph with four-color illustrations, and $(b)$ being the first book to publish the now ubiquitous problems in which students are given a NMR spectrum and an empirical formula and asked to deduce the molecular structure.

But the fact is that I was thoroughly upstaged shortly after publication, when still in 1959, a very different NMR book appeared on the scene, entitled High-resolution Nuclear Magnetic Resonance by John A. Pople, William G. Schneider, and Harold J. Bernstein (10). This book was itself to a degree ephemeral because of rapid experimental development of the field, but it still achieved a longer-term impact than otherwise might have been expected through its authoritative discussions of the basic theory of NMR, chemical shifts, spin-spin splitting, relaxation, and rate effects. One would presume that much of the theoretical part was written by John A. Pople, well-known for his work on applications of quantum mechanics to chemistry, who was then at the National Physical Laboratory at Teddington, UK. The extensive information on chemical applications was surely largely the work of William G. Schneider and Harold J. Bernstein at the National Research Council Canada (NRC) in Ottawa. The cooperative effort of the three authors says much for the acumen of NRC in getting into new areas of great promise.

The book by Pople, Schneider, and Bernstein (PSB, Fig. 1) was monumental. It was comprehensive and covered a wide range of applications using a wide range of NMR- active nuclei. At the same time, it supplied very authoritative, but not always user-friendly, theory for organic chemists. Many of those applications involved studies made by the authors at NRC. These included excellent and substantial work on the analysis of the shifts and couplings in a variety of organic heterocyclic compounds, such as pyridine, lutidine, quinoline, and isoquinoline, as well as substituted cyclohexanes. Hydrogen bonding was studied in considerable detail by changes in the chemical shifts of the acidic protons of carboxylic acids, as a function of concentration mostly in non-polar aprotic solvents. Related research was reported on the substantial changes in the proton shift of chloroform dissolved in aromatic solvents. Other important work involved changes in the relative keto-enol concentrations as a function of solvent.

Having already had some experience in organic chemical applications, I was especially interested in PSB's account of the theory of spin-spin splitting and how to extract spinspin couplings from non-first-order spectra. When I wrote my NMR book, I was at the level of the dogma on shifts and spin-spin couplings that is taught in most elementary organic courses today. One of the principal tenets of the dogma relating to shifts was that electronegative substituents caused downfield proton shifts. Other tenets for spin-spin splitting included the notion that protons with the same chemical shift do not split one another (but not why), the $n+1$ rule for predicting proton-proton splittings, and also that proton-proton couplings are normally not significant when the protons are separated by more than three bonds. However, I did mention in my book the seemingly anoma- 
lous $\mathrm{AA}^{\prime} \mathrm{XX}^{\prime}$ spectrum of 1,1-difluoroethene described by McConnell (11) and made it embarrassingly clear that I did not understand how it came about, although I was sufficiently interested to produce a higher resolution spectrum than the published one.

It should not be surprising that I was clearly an avid customer for PSB's methods for calculating spectral line positions. Although previously an advocate for organic chemists learning to apply Hückel MO theory to organic compounds (12), I needed a powerful catalyst for seeing the connection between the behavior of electrons in orbitals and of magnetic nuclei interacting with one another in a magnetic field. Fortunately, for my then colleague, Harden McConnell, this area of theory was like mother's milk and in a "mano a mano" struggle on July 4, 1956, he hoisted me over the energy barrier to use it. The ultimate result was a 105 page book (13) explaining in a way that I could understand a rather small number of pages of PSB. By the time I completed my manuscript, my copy of PSB was literally coming apart at the seams with the top of the pages deeply blackened, particularly in those areas covering the theory of NMR. Unfortunately, my manuscript was written and submitted just before it became commonplace to calculate and plot spectra as was done early on by Wiberg and Nist (14).

Others, such as Ray Lemieux (15) and Ted Schaefer (16) who achieved recognition of their own NMR research progress by way of the citation index approbations expressed strong appreciation for the contributions and inspiration provided to them by Schneider and Bernstein during the periods in which each worked at NRC.

The word seminal is used so much today in describing more or less new things in science that its real meaning is almost lost, but PSB's book sets a standard for the word by its timeliness, breadth, and depth of coverage at a crucial stage of NMR development. Furthermore, the book sparked the enthusiasm of chemists generally and it led them to demand more and better NMR spectrometers. The resulting market for machines turned out to be quite large and led to the early fierce and continuing competition among the instrument makers: Varian, Bruker, JEOL, and Nicolet (later GE) to provide customers with both routine and cutting-edge instrumentation representing the epitome of high technology.

Almost 60 years since the demonstration of NMR in the condensed phase $(17,18)$, the field is still growing almost explosively with applications in MRI (19), quantum computing (20), protein structure determinations (21), and optical detection of changes in force associated with excitation of nuclei in a magnetic field (22). The future of NMR is very bright indeed.

\section{References}

1. N. Gilbert and M.R. Lewis. Thermodynamics and the free energy of chemical substances. McGraw-Hill Book Company, New York. 1926.

2. L. Pauling and E.B. Wilson, Jr. Introduction to quantum mechanics, with applications to chemistry. McGraw-Hill Book Company, New York. 1935.

3. L. Pauling. The nature of the chemical bond and the structure of molecules and crystals. Cornell University Press, Ithaca, N.Y. 1939.

4. N.V. Sidgwick. The organic chemistry of nitrogen. Clarendon P., Oxford, UK. 1966.

5. L.P. Hammett. Physical organic chemistry. Reaction rates, equilibria and mechanisms. McGraw-Hill, New York. 1970.

6. A.R. Bader, H.S. Gutowsky, G.A. Williams, and P.E. Yankwich. J. Am. Chem. Soc. 78, 2385 (1956).

7. A.T. Bottini and J.D. Roberts. J. Org. Chem. 21, 1169 (1956).

8. J.D. Roberts. J. Am. Chem. Soc. 78, 4495 (1956).

9. J.D. Roberts. Nuclear magnetic resonance: applications to organic chemistry. McGraw-Hill, New York. 1959.

10. J.A. Pople, W.G. Schneider, and H.J. Bernstein. Highresolution nuclear magnetic resonance. McGraw-Hill, New York. 1959.

11. H.M. McConnell, A.D. McLean, and C.A. Reilly. J. Chem. Phys. 23, 1152 (1955).

12. J.D. Roberts. Notes on molecular orbital calculations. W.A. Benjamin, Inc., New York. 1961.

13. J.D. Roberts. An introduction to the analysis of spin-spin splitting in high-resolution nuclear magnetic resonance spectra. W.A. Benjamin, Inc., New York. 1961.

14. K.B. Wiberg and B.J. Nist. The interpretation of NMR spectra. W.A. Benjamin, Inc., New York. 1962.

15. R.U. Lemieux. Citation Classics, 26 (1980).

16. T. Schaefer. Citation Classics, 32 (1981).

17. E.M. Purcell, H.C. Torrey, and R.V. Pound. Phys. Rev. 69, 37 (1946).

18. F. Bloch, W.W. Hansen, and M. Packard. Phys. Rev. 70, 475 (1946).

19. C.A. Meriles, D. Sakellariou, A.H. Trabesinger, V. Demas, and V.A. Pines. Proc. Natl. Acad. Sci. U.S.A. 102, 1840 (2005)

20. D.G. Cory, A.F. Fahmy, and T.F. Havel. Proc. Natl. Acad. Sci. U.S.A. 94, 1634 (1997).

21. A. Bax. Protein Science, 12, 1 (2003).

22. L.A. Madsen, G.M. Leskowitz, and D.P. Weitekamp. Proc. Natl. Acad. Sci. U.S.A. 101, 2804 (2004). 